\title{
Local Immunity Status and Apoptosis Reactions in Endometrium of Women with a History of Non-Developing Pregnancy
}

\section{Chistyakova GN ${ }^{1}$, Remizova II ${ }^{1 *}$, Melkozerova OA2 , Pogorelko DV ${ }^{3}$, Dankova IV ${ }^{4}$ and Esareva AV $^{3}$}

${ }^{1}$ Department of Immunology and Clinical Microbiology, Mother and Child Care Ural Research Institution of Russia Public Health Ministry, Yekaterinburg, Russia

${ }^{2}$ Scientific Department of the Preservation of Reproductive Function, Mother and Child Care Ural Research Institution of Russia Public Health Ministry, Yekaterinburg, Russia

${ }^{3}$ Department of Gynecology, Mother and Child Care Ural Research Institution of Russia Public Health Ministry, Yekaterinburg, Russia

${ }^{4}$ Scientific Department of Intensive Care and Reanimation, Mother and Child Care Ural Research Institution of Russia Public Health Ministry, Yekaterinburg, Russia

${ }^{*}$ Corresponding author: Remizova Irina I, Department of Immunology and Clinical Microbiology Mother and Child Care Ural Research Institution of Russia Public Health Ministry, Yekaterinburg, Russia, Tel: 89502090 494; E-mail: Remizovall@yandex.ru

Received: August 30, 2017; Accepted: September 28, 2017; Published: October 05, 2017

Citation: Chistyakova GN, Remizova II, Melkozerova OA, Pogorelko DV, Dankova IV, et al. (2017) Local Immunity Status and Apoptosis Reactions in Endometrium of Women with a History of Non-Developing Pregnancy. Ann Clin Lab Res Vol.5:No.3:198.

\section{Abstract}

In order to estimate the status of local immunity of women with a history of non-developing pregnancy, we conducted a research of cytokine-producing cells (CD4+IFN-,$-+ \mathrm{CD} 4+\mathrm{IL}-4+)$ and apoptosis markers (AnV+/ $\mathrm{PI}--$, AnV+/PI+-, AnV-/PI+-cells) in endometrial biopsy material. In addition to this, we studied the number of activated blood mononuclears expressing CD95+ receptor. The research has shown that the development of chronic inflammation in endometrium is associated with anaerobic dysbiosis of vaginal microbiota coupled with impaired production of intracellular cytokines, a cytokine balance shift towards Th1-dependent immune response at the local level and an increase in production of proinflammatory mediators in blood serum.

A compensatory reaction limiting the number of activated cells in endometrium is expressed in an increased number of apoptosising mononuclears at different stages of cell death. A decrease in the number of cells demonstrating readiness to programmed cell death in peripheral blood indicates that potentially dangerous activated lymphocytes are preserved in circulation at the system level. Defining the polarization index of cytokineproducing cells and the number of endometrial mononuclears expressing Fas-antigen may be used as additional criteria for early detection of endometrial conditions.

Keywords: Chronic endometritis; Local immunity; Apoptosis markers; Intracellular cytokines

\section{Aim and Objective}

Determine immunological criteria of chronic endometrium inflammation in nonpregnant women with a history of nondeveloping pregnancy.

\section{Introduction}

According to some literature data, the incidence of chronic endometritis in women with a history of early reproductive losses reaches $70 \%$ of cases; detection of this condition associated with placental tissue remnants after an artificial abortion reaches $25.8 \%$, and $28.3 \%$ after a spontaneous abortion [1-4], which is related primarily to difficulties with morphological verification of diagnosis $[5,6]$. By consensus of obstetricians and gynaecologists in 2006 each case of nondeveloping pregnancy is regarded as being associated with chronic endometritis, both at the cause and the effect levels [7]

Latest research has shown that chronic pelvic inflammatory diseases are not accompanied by disruption of parameters of cellular and humoral immunity detected in peripheral blood. Thus, in order to determine functional status of endometrium, we need to assess the local immunity [8-10]. Bacterium-virus colonization of endometrium is the result of failure of the immune system to eliminate infectious agent; but at the same time its spread is limited due to effector properties of Tlymphocytes, NK-cells and macrophages. The local immunity of endometrium tissue changes under the influence of specific antigens, e.g. differentiation of T-helper cells into Th-1 and Th-2 subpopulations specializing in synthesis of pro- and antiinflammatory cytokines. A balance shift towards activation of Th-1 dependent immune response may lead to the development of severe inflammatory reactions in endometrium even with low concentration of infectious agent $[2,11]$. 
According to modern concept, normal growth and differentiation of endometrium cells take place only when the balance between proliferation and apoptosis is maintained. It is believed that suppression and disruption of apoptosis in endometrium may cause an uncontrollable cell proliferation, development of hyperplastic processes in endometrium and tumors. On the other hand, excessive apoptosis activation may lead to refractory thin endometrium in the presence of chronic inflammatory process. Peculiarities of local immunity and apoptosis in endometrium need further research.

\section{Materials and Methods}

Bacteriological and immunological examinations of 22 women of reproductive age diagnosed with chronic endometritis with a history of recurrent pregnancy loss $\left(1^{\text {st }}\right.$ major group) were conducted. A comparison group ( $2^{\text {nd }}$ group) consisted of 18 relatively healthy non-pregnant women.

All women provided written informed consent for biological sampling.

\section{Criteria for inclusion in the main group}

Women with a history of undeveloped pregnancy, suffering from chronic endometritis, confirmed histologically.

\section{Exclusion criteria}

Malignant neoplasms of any localization, Progressive uterine pregnancy in the first trimester, severe somatic pathology.

A study of genital tract biocenosis was performed using polymerase chain reaction in real-time mode by means of testing kits Proba NK and Femoflor-16 manufactured by DNKTechnologiya (Russia). Amplification and detection in real-time mode was conducted using IQ5 Multicolor Real-Time PCR Detection System by BIO-RAD (USA). Quantitative assessment of urogenital biota was represented in absolute ratio (Genome Equivalent-GE/per sample), as well as in relative ratio (\%) which were calculated using IQ5 Multicolor Real-Time PCR Detection System software by BIO-RAD (USA).

Linear range was as following:

- For ureaplasma 0-109 $\mathrm{GE} /$ sample

- For total/general bacterial mass $10^{4}-10^{10} \mathrm{GE} / \mathrm{sample}$

- For other microorganisms $10^{3}-10^{10} \mathrm{GE} /$ sample

Normocenosis was diagnosed with absolute number of Lactobacillus spp. $10^{6}-10^{8}$ and a relative ratio of $80 \%$ to $100 \%$ of total bacterial mass.

Relative normocenosis was diagnosed with absolute number of Lactobacillus spp. $10^{6}-10^{8}$ and a relative ratio of $80 \%$ to $100 \%$ of total bacterial mass and a presence of diagnostically significant anaerobic microorganisms titer $\left(>10^{4}\right.$ $\mathrm{GE} /$ sample). Whereas moderate dysbiosis-with absolute number of Lactobacillus spp. $10^{6}-10^{8}$ and a relative ratio from 20 to $80 \%$ of total bacterial mass; and severe dysbiosis-with a relative ratio of Lactobacillus spp. below $20 \%$ of total bacterial mass or with its absence. Anaerobic, aerobic or anaerobic- aerobic dysbiosis was diagnosed in case of prevalence of anaerobic and/or aerobic microflora.

Dark-red blood and endometrium tissue sampling (pipelle biopsy method) was performed between day seven and nine of menstrual cycle.

\section{Isolation of mononuclear cells from endometrial tissue}

$1 \mathrm{ml}$ of the obtained biopsy paste was placed in a tube with $100 \mathrm{U}$ of sodium heparin in $1 \mathrm{ml}$ of phosphate-buffered saline (PBS). The pipelopeptate in the FSB was mechanically ground and brought to a homogenized state, passing through a syringe through needles of a downward diameter. From the resulting endometrial homogenate, a fraction of mononuclear cells was isolated on a density gradient: $2 \mathrm{ml}$ of the homogenate was layered on $2 \mathrm{ml}$ ficoll verrographin and centrifuged for 40 minutes at $1500 \mathrm{rpm}$. After centrifugation, an opalescent ring of mononuclear cells was collected by a dispenser, transferred to a dry, clean tube and washed twice with PBS by centrifugation at $1500 \mathrm{rpm}$ for 15 minutes.

Immunophenotyping of lymphocytes in endometrial biopsy material was performed by flow laser cytofluorometry analyzer FACS Calibur by Becton Dickinson (USA) using monoclonal antibodies kits, conjugated with fluorescein isothiocyanate (FITC) and phycoerythrin (PE) by the same manufacturer. We determined the content of cytokineproducing monocytes CD4+IFN-,$-+ C D 4+I L-4+$. In addition to this, in blood mononuclears we evaluated the level of expression of markers of cell readiness to apoptosis (CD95) in both total lymphocyte pool and T-cells population.

The intensity of apoptosis reactions was evaluated by cells' simultaneous binding of two markers- annexin $\mathrm{V}(\mathrm{AnV})$ and propidium iodide (PI) by means of Annexin V-FITC Apoptosis Detection Kit I (BD Pharmingem ${ }^{\mathrm{TM}}$, USA) using flow cytometry in CellQuest software. Each sample was analyzed by 10,000 events. The results were represented in percentage of the total number of cells. Annexin $V$ was used for detecting lymphocytes that had started apoptosis (AnV+ cells); and propidium iodide was used as a marker of cell viability (AnV-PIcells) and cellular necrosis (AnV-PI+ cells).

The content of cell-to-cell cooperation mediators in blood serum was evaluated by enzyme-linked immunosorbent assay (ELISA) in accordance with the recommendations of the sets manufacturers:

- Level of pro- and anti-inflammatory cytokines (IFN- $\gamma$, IL-6, IL-8, TNF- $\alpha$, IL-4 was tested with kits by ZAO Vector-Best (Novosibirsk-117, Russia).

- Concentration of C-reactive protein (CRP) was tested using reagents by Biomerica (USA).

Detection of study's results was performed via Multiskan MCC/340 enzyme-immunoassay analyzer by Labsystems (Finland).

Statistical processing of the study results was performed with the help of the application program packages Microsoft 
Excel (2007) and Statistica for Windows 6.0 (StatSoft, Tulsa, OK, USA). Quantitative data were presented by median (Me) and the lower and upper quartiles (25th and 75th percentiles, P25-P75).

Testing of statistical hypotheses for the absence of intergroup differences of quantitative traits was performed using Mann-Whitney U-test. For indicators characterizing qualitative traits, we specified absolute ratio and relative value in percentage; verification of statistical hypotheses was performed using chi-square $(\chi 2)$ criterion. The critical level of significant discrepancy ( $p)$, in which the null hypothesis of no difference was rejected and the alternative one was accepted, was set equal to 0.05 .

\section{Results}

Median age of all examined women was comparable (29.36 \pm 4.58 vs $33.5 \pm 3.3$ years in the comparison group, $p>0.05)$. Both groups had predominately multigravida women $(95.5 \%$ and $72.2 \%, p=0.05)$.

The incidence of diagnosed urogenital infections in patients with chronic endometritis and in relatively healthy women did not have proven difference. Detection of urogenital infections agents was as following: $M$. genitalium $-22.7 \%$ and $11.1 \%, U$. urealiticum-31.8\% and $16.7 \%$, Ch. tracomatis $-9.1 \%$ and $5.5 \%$ in the 1 st and the 2 nd groups ( $p>0.05$ ) respectively.

A molecular-genetic study of urogenital microbiota showed microflora imbalance in over half of the patients with chronic endometritis (59.1\%). Dysbiotic manifestations in vaginal micro biocenosis included sharp decrease in quantity of lactoflora and dominance of obligate anaerobic component. Nearly a quarter of the women demonstrated severe anaerobic dysbiosis (22.7\%), every 1 in 3 had moderate anaerobic dysbiosis (36.4\%), $13.6 \%$ of women had relative normocenosis and $27.3 \%$ had absolute normocenosis. Among obligate anaerobic microorganisms, Gardnerella vaginalis/ Prevotellabivia/Porphyromonas spp. and Eubacterium spp. predominated- $38.4 \%$, which are proven to have high specificity for bacterial vaginosis. Ureaplasma (urealyticum +parvum) was detected in $23.1 \%$ of cases, while Atopobium vaginae- in $9.1 \%$ of cases. All women of the comparison group had absolute normocenosis.

Detection of cytokine expression level of whole blood cells allows us to characterize the secretory activity ability of immunocytes and to identify biosynthesis defects of a number of major cell-to-cell cooperation mediators. And evaluation of spontaneous expression of cytokines by immunocompetent cells shows how strongly these cells are activated in vivo, while mitogen-induced expression allows us to assess potential ability of cytokine-producing cells to produce signal molecules in response to an extra stimulus which characterizes functional reserve of the immune system.

While assessing the expression level of intracellular cytokines in endometrium tissue, it was established that in women with chronic endometritis the number of $\mathrm{T}$ lymphocytes expressing IFN- $\gamma$ was not significantly different.

Furthermore, we observed a significant decrease of percentage of regulatory CD4+IL-4+ cells during both spontaneous test and stimulation (the cells were stimulated with Leukocyte Activation Coctail containing the protein kinase C activator C forbol-12-myristate-13-acetate (PMA) in combination with calcium ionophore ionomycin), which resulted in a significant shift of the polarization index (CD4+IFN- $\gamma+/ \mathrm{CD} 4+\mathrm{IL}-4+)$ towards Th1-dependent immune response compared to the results of relatively healthy women (Table 1).

Table 1 Spontaneous and induced cytokine production in women with chronic endometritis, Me (LQ-UQ)

\begin{tabular}{|c|c|c|c|}
\hline Parameters & Group 1 (n=22) & Group 2 (n=18) & $\mathbf{P}$ \\
\hline CD4+IFN- $\gamma+$ spont., $\%$ & $1.59(1.54-2.8)$ & $1.51(0.61-1.68)$ & - \\
\hline CD4+IL-4+ spont., $\%$ & $1.03(0.96-1.52)$ & $2.5(0.71-2.65)$ & 0.03 \\
\hline CD4+IFN- + +/CD4+IL-4+ spont., y.e. & $1.5(1.26-1.65)$ & $0.54(0.52-0.76)$ & 0.001 \\
\hline $\mathrm{CD} 4+\mathrm{IFN}-\gamma+$ ind., $\%$ & $3.37(2.02-4.98)$ & $4.2(0.80-4.21)$ & - \\
\hline CD4+IL-4+ ind., $\%$ & $3.48(2.41-4.66)$ & $5.6(1.43-6.46)$ & 0.002 \\
\hline CD4+IFN- $\gamma+/ C D 4+\mid L-4+$ ind., y.e. & $1.02(0.94-1.23)$ & $0.88(0.51-0.84)$ & 0.01 \\
\hline
\end{tabular}

Using statistical analysis, we established that ratio between IFN- $\gamma$ and IL-4-producing endometrial lymphocytes Th1/Th2 exceeding 0.92 conventional units indicates disorders of local immunity in women with endometrium abnormalities; while with Th1/Th2 less than 0.92 conventional units it indicates that there are no signs of abnormalities. In $83.6 \%$ of cases the presence of inflammation was confirmed by a histologic study. Apoptosis is a universal physiological process whose defense mechanism aims to start self-destruction of pathologically changed, infected, mutated cells or those cells which have executed their biological function. Normal growth and differentiation of endometrium cells occur in the presence of a balanced ratio between proliferation and programmed cell death which is regulated by a large number of signal molecules launching apoptosis [2,12,13]. 
According to the immunological analysis of endometrium tissue, the quantity of cells at the stage of necrosis did not show statistically significant difference both in women with chronic endometritis and in healthy women (Table 2).

Table 2 Determination of apoptosis markers in the endometrial biopsy and serum in women with chronic endometritis, Me (LQUQ).

\begin{tabular}{|c|c|c|c|c|}
\hline \multicolumn{2}{|l|}{ Parameters } & Group 1 ( $n=22)$ & Group 2 (n=18) & $\mathbf{P}$ \\
\hline \multicolumn{5}{|c|}{ Endometrial biopsy } \\
\hline \multicolumn{2}{|c|}{ The total number of cells in apoptosis (AnV+/PI++AnV+/PI-), \% } & $14.2(3.98-19.54)$ & $1.99(1.25-2.34)$ & 0.0001 \\
\hline \multicolumn{2}{|c|}{ The number of cells in the early stage of apoptosis (AnV+/PI-),\% } & $4.39(1.69-10.65)$ & $2.2(1.5-3.4)$ & 0.017 \\
\hline \multicolumn{2}{|c|}{ The number of cells in the late stage of apoptosis $(\mathrm{AnV}+/ \mathrm{PI}+), \%$} & $19.63(5.8-29.37)$ & $4.19(2.75-5.43)$ & 0.001 \\
\hline \multicolumn{2}{|c|}{ Number of cells at the stage of necrosis (AnV-/PI+), \% } & $0.57(0.32-1.05)$ & $0.39(0.26-0.71)$ & - \\
\hline \multicolumn{5}{|c|}{ Peripheral blood } \\
\hline \multirow[t]{2}{*}{ CD95+ } & $\%$ & $5.5(4.75-7.0)$ & $11.0(10.0-16.0)$ & 0.001 \\
\hline & $10^{9} / \mathrm{L}$ & $0.15(0.11-0.17)$ & $0.26(0.24-0.65)$ & 0.0001 \\
\hline \multirow[t]{2}{*}{ CD3+CD95+ } & $\%$ & $4.5(2.5-5.25)$ & $9.0(6.0-13.0)$ & 0.0001 \\
\hline & $10^{9} / \mathrm{L}$ & $0.09(0.04-0.12)$ & $0.31(0.15-0.53)$ & 0.0001 \\
\hline \multirow[t]{2}{*}{ CD4+CD95+ } & $\%$ & $2.5(2.0-4.25)$ & $6.0(4.0-8.0)$ & 0.002 \\
\hline & $10^{9} / \mathrm{L}$ & $0.09(0.06-0.09)$ & $0.21(0.10-0.32)$ & 0.002 \\
\hline \multirow[t]{2}{*}{ CD8+CD95+ } & $\%$ & $1(0-1.25)$ & $3.5(2.0-5.0)$ & 0.002 \\
\hline & $10^{9} / \mathrm{L}$ & $0.01(0.0-0.04)$ & $0.12(0.08-0.13)$ & 0.0001 \\
\hline
\end{tabular}

The total number of cells at the stage of apoptosis, as well as percentage of lymphocytes which entered an early or late stage of programmed cell death exceeded the corresponding results of the comparison group by $4.7,7.1$ and 2.0 times. It is presumably connected with a disbalance of pro- and antioxidant systems, hypoxia typical for chronic inflammatory process in endometrium. Moreover, we all know that immune apoptosis develops in activated cells and is crucial for the completion of immune response [14]. Stimulation of apoptosis processes of lymphocytes, being one of the powerful mechanisms of controlling cell activation, is essentially a regulating factor in response to activation and proliferation of immunocompetent cells in case of endometrium abnormality.

A peripheral blood study of women with chronic endometritis showed a decrease in quantity of CD95+ cells both in total lymphocyte pool, and in CD3, CD4, CD8 populations, which indicates a decrease in reception of apoptosis molecules.

The intensity of Fas-antigen expression does not reflect level of apoptosis, but indicates only potential readiness of lymphocytes for apoptogenic signal reception.

With an increased amount of activated cells in endometrium tissue in women with chronic endometritis an increase of concentration TNF- $\alpha$, IL- 6, IL- 8 and CRP in blood serum was recorded (Table 3 ). And at the same time the level of IFN- $\gamma$ in serum was significantly low.
Table 3 The level of cytokines and CRP in the serum of peripheral blood in women with chronic endometritis, Me (LQUQ).

\begin{tabular}{|c|l|l|l|}
\hline Parameters & $\begin{array}{l}\text { Group } \\
(\mathbf{n = 2 2})\end{array}$ & $\begin{array}{l}\text { Group } \\
(\mathbf{n}=18)\end{array}$ & $\mathbf{P}$ \\
\hline TNF- $\alpha, \mathrm{pg} / \mathrm{ml}$ & $\begin{array}{l}5.73 \\
(3.87-7.04)\end{array}$ & $\begin{array}{l}1.69 \\
(1.39-1.98)\end{array}$ & 0.001 \\
\hline IFN- $\mathrm{p}, \mathrm{pg} / \mathrm{ml}$ & $\begin{array}{l}3.8 \\
(1.7-10.25)\end{array}$ & $\begin{array}{l}18.7 \\
(15.5-23.63)\end{array}$ & 0.003 \\
\hline $\mathrm{IL}-6, \mathrm{pg} / \mathrm{ml}$ & $\begin{array}{l}6.71 \\
(5.06-8.62)\end{array}$ & $\begin{array}{l}4.38 \\
(2.68-5.61)\end{array}$ & 0.006 \\
\hline $\mathrm{IL}-8, \mathrm{pg} / \mathrm{ml}$ & $\begin{array}{l}60.03 \\
(23.72-108.0)\end{array}$ & $\begin{array}{l}13.80 \\
(11.32-14.35)\end{array}$ & 0.002 \\
\hline $\mathrm{CRP}, \mathrm{mg} / \mathrm{l}$ & $\begin{array}{l}0.03 \\
(0.02-0.13)\end{array}$ & $\begin{array}{l}0.02 \\
(0.01-0.02)\end{array}$ & 0.002 \\
\hline
\end{tabular}

Data were presented as a median $(\mathrm{Me})$ and lower and upper quartiles $\left(25^{\text {th }}\right.$ and $75^{\text {th }}$ percentile, $L Q$ and $U Q$ ); $P$-level of significance of differences between groups (criterion Mann-Whitney)

\section{Discussion}

Among major causative factors of chronic endometritis, infectious one should be pointed out in the first place. Results of the numerous bacteriological studies in gynecology show that in present conditions, chronic endometritis is characterized by changes of etiological structure with 
increasing significance of viral and potentially pathogenic microflora, increased frequency of mixed infection, as well as growth in microflora resistance to drug treatment $[15,16]$.

According to received data, previously treated sexually transmitted infectious diseases in patients with chronic endometritis and in relatively healthy women were recorded with equal frequency. Nevertheless, every 1 in 2 women with chronic endometritis was diagnosed with anaerobic dysbiosis, while women of the comparison group did not demonstrate any disorders in micro biocenosis of vaginal microflora.

The presence of bacterium-virus colonization in endometrium, as a rule, results from inability of the immune system and nonspecific body defenses (complement system, phagocytosis) to eliminate an infectious agent entirely, which leads to microorganisms persistence characterized by the appearance of mononuclear phagocytes, natural killer cells, synthesizing proinflammatory cytokines in the area of inflammation $[10,17]$.

An immunological study of women with chronic endometritis showed that persistence of potentially pathogenic microorganisms is accompanied by a change of functional activity of immunocompetent cells.

All women with chronic endometritis had a decrease in spontaneous level of T-lymphocytes expressing regulatory cytokines (IL-4) which indicates insufficient production of intracellular factors mediating Th2-pathway of immune response. On the other hand, a significant decrease in the number of $\mathrm{CD} 3+\mathrm{IL}-4+$ cells under stimulation indicated a decrease of functional reserve of immunocompetent cells. Using discriminant analysis, we established a threshold of polarization index of cytokine-producing cells 10.92 conventional units), exceedance of which allowed us to suggest disorders at the level of local immunity in women with endometrium abnormalities. Similar results were obtained in a number of other studies. High ratios of Th1/Th2 production of intracellular cytokines in women with recurrent spontaneous abortions: IFN- $\gamma+/ \mathrm{IL}-4+$, TNF- $\alpha+/ \mathrm{IL}-4+$ and TNF- $\alpha+/ \mathrm{IL}-10+$ in CD3+/CD8-T cells [18]; CD56+/ IFN- $\gamma+/$ TNF- $\alpha+$, CD56 +/TNF- $\alpha$ $+/ G M-C S F+[19]$.

A significant increase in the production of proinflammatory mediators TNF- $\alpha, \mathrm{IL}-6$ and IL- 8 , as well as C-reactive protein suggested inflammatory orientation of cell responses in women with non-developing pregnancy, which correlates with data by a number of Russian and foreign scientists [20-22]. Herington reports on studies that indicate a link between elevated levels of serum IL-6 and the presence of endometriosis. Tortorella et al. demonstrated an increase in the level of proinflammatory cytokines in menstrual flow of women with $\mathrm{CE}$. The authors concluded that the experimental dosing of IL- 6 and TNF- $\alpha$ appears to have a high throughput for Kargamanova's study attests to high levels of proinflammatory cytokines with a predominance of IL1 $\beta$ and IL6 in acute endometritis in endometrial aspirate. The levels of proinflammatory cytokines in the aspirate from the uterine cavity were increased 5-8 times, compared to serum (3-5 times), which confirms a more pronounced local inflammatory reaction.

However, during our study concentration of IFN- $\gamma$ remained low, which is likely due to cytotoxic reaction of T-lymphocytes to lysis of infected cells by NK-cells, macrophages and polymorphonucleocytes mediated by antibodies. Therefore, increase in the production of TNF- $\alpha$, IL- 6 , IL- 8 and CRP results from stimulation from macrophages and neutrophils by endotoxin of gram-negative bacteria.

\section{Conclusion}

Modern views on the pathogenesis of CE are based on information on the ability of individual infectious agents to not only initiate chronic inflammation in the endometrium, but also interfere with the mechanisms of apoptosis of host cells $[23,24]$. According to Romero et al. [25], the products of the vital activity of infectious agents in microbial invasion, inducing proinflammatory mediators-cytokines and chemokines, can induce apoptosis of the trophoblast and a cascade of events leading to loss of the embryo.

In the literature there is evidence that the imbalance of proand antiapoptical factors in uterine hyperplastic processes is associated with a progressive decrease in the ability of cells to apoptosis. Petrov demonstrated that with a hyperplastic macro-type of chronic endometritis in the peripheral blood, a reduced level of lymphocyte expression of inducers of apoptosis CD95+ is recorded [23]. In our study an increased number of endometrial cells at different stages of apoptosis and a decreased number of T-lymphocytes population expressing marker of readiness to apoptosis in peripheral blood confirmed inflammatory process in women with chronic endometritis.

Thus, development of a chronic inflammation in endometrium is associated with anaerobic dysbiosis of vaginal microbiota coupled with impaired production of intracellular cytokines, a cytokine balance shift towards Th1-dependent immune response at the local level and an increased production of proinflammatory mediators in blood serum. A compensatory reaction limiting the number of activated cells in endometrium is expressed by increase of apoptosising mononuclears at different stages of cell death. A decrease in the number of cells demonstrating readiness to programmed cell death in peripheral blood indicates that potentially dangerous activated lymphocytes are preserved in circulation at the system level. Defining the polarization index of cytokineproducing cells and the number of endometrial mononuclears expressing Fas-antigen may be used as additional criteria for early detection of endometrial conditions. Activation of local apoptosis processes in endometrium with chronic endometritis, impaired production of intracellular cytokines, cytokine balance shift towards Th1-dependent immune response may result in development of refractory thin endometrium having low implant potential which, from the immunological perspective, determines poor reproductive prognosis for every case of a non-developing pregnancy. 


\section{Conflict of Interest}

The authors report no declaration of interest.

\section{References}

1. Petrov YA (2011) The role of immune disorders in the genesis of chronic endometritis. Bulletin of the Russian University of Peoples' Friendship. Medicine 6: 282-289.

2. Pluzhnikova TA, Komarov EK (2012) Diagnosis and treatment of chronic endometritis in women with miscarriage in history. J Obstet Women's Dis 61: 52-56.

3. Plyasunova MP, Khlybova SV (2013) Chronic endometritis as one of the actual problems in modern gynecology. Vyatsky Med Bull 1: 44-53.

4. McQueen DB, Bernardi LA, Stephenson MD (2014) Chronic endometritis in women with recurrent early pregnancy loss and/or fetal demise. Fertil Steril 101: 1026-1030.

5. Bouet PE, El-Hachem H, Monceau E, Gariépy G, Kadoch IJ, et al. (2016) Chronic endometritis in women with recurrent pregnancy loss and recurrent implantation failure: Prevalence and role of office hysteroscopy and immunohistochemistry in diagnosis. Fertil Steril 105: 106-110.

6. Park HJ, Kim YS, Yoon TK, Lee WS (2016) Chronic endometritis and infertility. Clin Exp Reprod Med 43: 185-192.

7. XVIII FIGO Congress of Gynecology and Obstetrics (2006) Kuala Lumpur, Malaysia.

8. Vicetti Miguel RD, Chivukula M, Krishnamurti U, Amortegui AJ, Kant JA, et al. (2011) Limitations of the criteria used to diagnose histologic endometritis in epidemiologic pelvic inflammatory disease research. Pathol Res Pract 207: 680-685.

9. Katkova NY, Grechkanyov GO, Kachalina TS, Kuptsova ES, Andosova LD, et al. (2016) Treatment of the hypoplastic variant of chronic endometritis: Arguments against antibacterial therapy CTM 8: 99-102.

10. Radzinsky VE, Petrov YA, Kalinina EA, Shirokova DV, Polina ML (2017) Pathogenetic features of macrotypes of chronic endometritis. Kazan Med Zh 98: 27-34.

11. Skvortsova MY, Podzolkova NM (2010) Prophylaxis of reproductive losses and complications of gestation in patients with miscarriage. Gynecology 1: 46-49.

12. Kwak-Kim JY, Chung-bang HS, Ng SC, Ntrivalas EI, Mangubat CP, et al. (2003) Increased $T$ helper 1 cytokine responses by circulating losses and infertile women with multiple implantation failures after IVF. Hum Reprod 18: 767-773.
13. Fukui A, Kwak-Kim J, Ntrivalas E, Gilman-Sachs A, Lee SK, et al. (2008) Intracellular cytokine expression of peripheral blood natural killer cell subsets in women with recurrent spontaneous abortions and implantation failures. Fertil Steril 89: 157-165.

14. Amezcua CA, Lu JJ, Felix JC, Stanczyk FZ, Zheng W (2000) Apoptosis may be an early event of progestin therapy for endometrial hyperplasia. Gyn Oncology 79: 169-176.

15. Chistyakova GN, Tarasova MN, Gazieva IA, Remizova II, Pogorelko DV (2013) Features of apoptosis of lymphocytes in women with a regressing pregnancy in the anamnesis. Reproduction Problems 4: 27-30.

16. Sukhikh GT, Shurshalina AV (2010) Chronic endometritis: A guide- Moscow: GEOTAR-Media, 64.

17. Taylor BD, Ness RB, Darville T, Haggerty CL (2011) Microbial correlates of delayed care for pelvic inflammatory disease. Sex Transm Dis 38: 434-438

18. Cicinelli $E$, De-Ziegler $D$, Nicoletti R, Tinelli $R$, Saliani $N$, et al. Poor reliability of vaginal and endocervical cultures for evaluating microbiology of endometrial cavity in women with chronic endometritis. Gynecol Obstet Invest 68: 108-115.

19. Mote PA, Balleine RL, McGowan EM, Clarke CL (2011) Colocalization of progesterone receptors $A$ and $B$ by dual immunofluorescent histochemistry in human endometrium during the menstrual cycle. J Clin Endoc Metab 84: 2963-2971.

20. Herington JL, Bruner-Tran KL, Lucas JA, Osteen KG (2011) Immune interactions in endometriosis. Expert Rev Clin Immunol 7: 611-626.

21. Tortorella C, Piazzolla $G$, Matteo $M$, Pinto $V$, Tinelli $R$, et al. (2014) Interleukin-6, interleukin-1 $\beta$, and tumor necrosis factor $\alpha$ in menstrual effluents as biomarkers of chronic endometritis. Fertil Steril 101: 242-247.

22. Kagramanova ZA, Malinovskaya VV, Vyzhlova EN, Lanshakova PE (2016) New directions in the diagnosis and treatment of endometritis Immunopathol Allergol Infectol 1: 64-77

23. Petrov YA (2011) Nuances of immunological reorganization in chronic endometritis. Valeology 4: 44-50.

24. Margalioth EJ, Ben-Chetrit A, Gal M, Eldar-Geva T (2006) Investigation and treatment of repeated implantation failure following IVF-ET. Hum Reprod 21: 3036-3043.

25. Romero R, Espinoza J, Mazor M (2004) Can endometrial infection/inflammation explains implantation failure, spontaneous abortion, and preterm birth after in vitro fertilization? Fertil Steril 82: 799-804. 